\title{
Influence of Weather and Purity of Plasticizer on Degradation of Cassava Starch Bioplastics in Natural Environmental Conditions
}

\author{
Michael Ahimbisibwe1,2, Noble Banadda ${ }^{3}$, Jeffrey Seay ${ }^{4 *}$, Betty Nabuuma², Evans Atwijukire1, \\ Enoch Wembabazi', Ephraim Nuwamanya ${ }^{1,2}$
}

${ }^{1}$ National Crops Resources Research Institute Namulonge, Kampala, Uganda

${ }^{2}$ Makerere University, College of Engineering, Design Art and Technology (CEDAT), Kampala, Uganda

${ }^{3}$ Makerere University, College of Agriculture and Environmental Sciences (CAES), Kampala, Uganda

${ }^{4}$ University of Kentucky, Paducah, KY, USA

Email: *jeffrey.seay@uky.edu

How to cite this paper: Ahimbisibwe, M., Banadda, N., Seay, J., Nabuuma, B., Atwijukire, E., Wembabazi, E. and Nuwamanya, E. (2019) Influence of Weather and Purity of Plasticizer on Degradation of Cassava Starch Bioplastics in Natural Environmental Conditions. Journal of Agricultural Chemistry and Environment, 8, 237-250.

https://doi.org/10.4236/jacen.2019.84018

Received: October 1, 2019

Accepted: November 29, 2019

Published: November 29, 2019

Copyright $\odot 2019$ by author(s) and Scientific Research Publishing Inc. This work is licensed under the Creative Commons Attribution International License (CC BY 4.0).

http://creativecommons.org/licenses/by/4.0/

\begin{abstract}
The threat posed by plastics to the environment has prompted the development of bioplastics. Starch plasticized by glycerol is a key renewable resource in the production of high-quality bioplastics. Previous studies have availed information on the mechanical quality of starch-based bioplastics however there is limited information about their degradation pattern in the natural environment which this research presents. Bioplastics were buried in holes in loam sandy soil and weekly photographic data and weight were collected to reveal the effect of degradation. Weather parameters of rainfall, temperature, relative humidity, sunshine intensity and sunshine hours were recorded to establish influence of weather on degradation. A control set up in the laboratory was used to compare the results. Over time the tests revealed that as the hydrophilic enzymes break down the bioplastic, its weight initially increases (up to 87\%) due to absorption of moisture and after saturation, the bioplastic is disintegrated which initiates decomposition and the bioplastic weight is steadily reduced. Degradation was further enhanced by invasion of soil organisms like worms, termites among other soil microbes. Rainfall $(r=0.857)$ increased the moisture in the soil which initially increased the weight of the bioplastic up to a point when the hydrophilic enzymes set into breakdown the bioplastic then the weight started to drop. This was the same case for relative humidity $(r=-0.04)$ however; the sunlight intensity $(r=515)$ and hours of illumination indirectly affect the process by influencing microbial activity. An increase in the sunshine intensity increased the activity of soil organisms up to a point beyond which increased exposure caused the organisms to burrow deeper in the soil. Increase in microbial activity increased the rate of degrada-
\end{abstract}


tion of the buried bioplastics which took five to ten weeks to fully decompose (98.3\%). The reduced time of degradation means that starch-based bioplastics have a high potential as sustainable substitute for petroleum-based plastics.

\section{Keywords}

Bioplastic, Degradability, Purified Glycerol

\section{Introduction}

Petroleum-based plastic is tough, light, flexible, versatile, moisture resistant and relatively inexpensive. These qualities have seen both its production and use rise to meet diverse human needs, ranging from packaging to electronic device components [1]. However, this great resource takes a very long time, often 100 years or more to degrade under natural environmental conditions [2]. All plastic is degradable but when its period of disintegration is outside the human time frame, it is considered non degradable [3]. Additionally, petroleum-based plastic comes with negative environmental impacts including: persistence in soil which alters the soil structure; destroying biota; and distorting the general beauty of the landscape. Plastic debris ends up in water bodies and is responsible for the death various aquatic animals like fish, zooplanktons, amphibians, mammals and water birds [4]. It has been observed that ingestion of the plastic debris kills the birds, fish, whales and turtles, owing to the numerous carcasses seen with intact plastic materials in their digestive system [5]. Besides, the hazards of plastic in the human and animal food chain, the plastic, if poorly disposed especially in urban areas, end up in sewer lines, resulting in blockage of drainage channels, creating breeding grounds for mosquitoes and other vectors increasing disease prevalence. Blockage of drainage channels further exacerbates flood prevalence, leading to unhealthy suburbs with increased cost of waste and flood management.

In the face of this growing environmental problem, the need for renewable environmentally benign and non-persistent alternative packaging materials is urgent. Efforts to blend petroleum-based plastic with natural polymers, especially starch, in order to shorten their life time have shown great potential [6]. Other bioplastics have been developed from protein resins, plant lignin and cellulose [7]. Some studies have ventured into producing the bioplastics from animal fat and lipids [8] [9]. These efforts are all geared toward creating a sustainable solution to challenges presented by the persistent petroleumbased plastics. In particular, starch, which is a major carbohydrate source in plant tubers and cereals provides a more promising option for production of bioplastics [8] [9]. Starch is naturally abundant, available at low cost, and once plasticized, its polymer flexibility other mechanical properties are greatly enhanced. Plasticizing agents like glycerol are able to break down hydrogen bonds in starch forming multiple monomers that constitute the starch gra- 
nules into a polymer. Different bioplastics have been produced from starch which includes: Thermal plastic starch (TPS), starch blends with biodegradable polyesters like Polylactic acid (PLA) Polycaprolactone \& Ecoflex among others with promising quality [10] [11]. Glycerol is generated as a byproduct in the biodiesel production whose direct disposal has negative environmental effects but once purified it has multiple applications in cosmetics, polymers, pharmaceutical [12] and food. Use of this glycerol as a plasticizer has environmental benefits of reduced pollution and production of an environment-friendly bioplastic. The ability of bioplastics to degrade in relatively shorter periods of time is a prime advantage of these renewable alternatives to petroleum-based plastics.

Degradation of bioplastic is carried out by enzymes produced by microorganisms that operate under particular optimal conditions. The primary factors influencing degradation of bioplastics are: polymer characteristics; type of microorganism; and nature of pretreatment. The polymer characteristics of interest are: mobility; tactility; crystallinity; molecular weight; type of functional units; and nature of additives like plasticizers [13]. The hydrophilic enzymes that breakdown starch, operate optimally in humid or high moisture conditions. Starch is broken down by amylase enzyme, secreted either by soil organisms like worms, bacteria or fungi in their extracellular environment. This enzyme helps to digest the insoluble starch to soluble end products like glucose and maltose, which are then absorbed by the microbial cells. During starch degradation, the large chains are first broken into smaller segments which drastically weaken the bonds, reducing the viscosity and hence leading to liquefaction. This is followed by formation of mono-, di- or tri-saccharides under the process of saccharifaction [13]. Temperature, light intensity, water and oxygen availability enhance microbial activity in the degradation process. Another important factor in the degradation of starch-based bioplastics is the hydrophilicity of the two starch monomers: amylose and amylopectin. Even though, hydrophilicity hinders compatibility of these monomers with hydrophobic polymers [14], this property predisposes the starch to hydrolysis by hydrophilic enzymes, hence improving polymer biodegradation.

The generated bioplastic degrades readily in water and can quickly be assimilated in the soil. This in combination with the reduced mechanical strength limits the application of the bioplastic film to dry light weight packaging of dry food, electronics, clothing among other dry packaging uses [11]. The bioplastic gel before drying and molding can also be used as a coating for paper to reinforce paper bags with a layer that increases moisture the paper bag's moisture and oil retention.

Numerous in vitro studies on enzymatic degradation of bioplastics have been done but little is compiled about natural environment degradability [13] [15] [16]. Information on starch bioplastic degradability informs release patterns of bioplastic to the environment and guides design and manufacture of different bioplastic products based on required degradation rates. Therefore, this study 
was carried out to specifically assess the degradability of starch based bioplastics in soil, under varying weather conditions together with laboratory based experiments in water and soil.

\section{Materials and Methods}

The bioplastics were made using cassava starch, glycerol and either hydrochloric acid $(\mathrm{HCl})$ or acetic acid as a hydrolyzing agent. Starch was extracted from peels of freshly harvested cassava roots from a field at National Crops Resources Research Institute in Central Uganda East Africa. The cassava peels were extracted with $0.1 \mathrm{M} \mathrm{NaCl}$ using a commercial warring blender (Warring, New Hartford, USA) and the homogenate was sieved through a triple layer muslin cloth [17]. The starch was dried in an air-forced oven (Model GP150SSF3OOHYD, Serial 96LOO7 Cheshire England) at $60^{\circ} \mathrm{C}$ for $24 \mathrm{hrs}$ before use. Two types of glycerol were used, Analytical Grade (AG) purchased from local market (control) and locally purified glycerol from waste vegetable oil following the method of Nanda [18] with modification. The other reagents used ( $\mathrm{HCl}$, Acetic Acid, AG glycerol, $\mathrm{NaCl}$ ) were obtained from the Loba Chemie Laboratory Reagents and Fine Chemicals and Sigma Aldrich bought from a local store. For each bioplastic type, $30 \mathrm{~g}$ of starch was mixed in $400 \mathrm{ml}$ of distilled water to form a uniform mixture, to this mixture, $15 \mathrm{ml}$ of an acid $(0.1 \mathrm{M})$ were added followed by $10 \mathrm{ml}$ of glycerol. The resultant paste was then heated in an $800 \mathrm{ml}$ glass beaker on a heating block (Model: Fabr-Nr 644006 Staufen German) at $120^{\circ} \mathrm{C}$ for 45 minutes. The paste after cooling for about 10 minutes was gently poured on a $\left(30 \mathrm{~cm}^{\star} 15\right.$ $\mathrm{cm}$ ) plastic tray, spread with a stirring rod and dried in an oven (Model GP150SSF3OOHYD, Serial 96LOO7 Cheshire England) at $60^{\circ} \mathrm{C}$ for 18 hours [19]. The treatment for the other types of bioplastics is shown in Table 1.

The bioplastics were cut into $3 \mathrm{~cm}^{2}$ and $10 \mathrm{~cm}^{2}$ pieces for laboratory and natural environment experiments respectively. Initial weights of the bioplastics were measured before burying in the soil. Weekly weight measurements and photographs of the bioplastics were taken to reveal the effect of degradation. The different bioplastics were put under three degradation treatments: the $1^{\text {st }}$, the bioplastics were soaked in $100 \mathrm{ml}$ of water (distilled and tap water) in $200 \mathrm{ml}$ beakers and was left on the bench in the laboratory with room temperature $\left(24^{\circ} \mathrm{C}-26^{\circ} \mathrm{C}\right)$. The $2 \mathrm{nd}$ set of bioplastics was buried 3 inches deep in the $500 \mathrm{gm}$ soil on foil plates in the laboratory and $60 \mathrm{mls}$ of water were added weekly to maintain moisture levels at $60 \%$ while the 3 rd set of bioplastics was subjected to natural environmental conditions. The bioplastic pieces were rolled in a polyester porous cloth mesh and then buried in holes of $30 \mathrm{~cm}$ deep, $30 \mathrm{~cm}$ long and 30 $\mathrm{cm}$ wide at the in Namulonge, Wakiso District in Uganda at a weather station for eleven weeks during a period extending from September to December 2017. Data on changes in weather pattern for parameters of rainfall, temperature, relative humidity and sunshine hours were collected to assess the effect on weather on degradation. 
Table 1. Treatment of the produced bioplastics.

\begin{tabular}{ccccc}
\hline Bioplastic & Starch $(\mathrm{g})$ & Water $(\mathrm{ml})$ & Type of Acid & Type of Glycerol \\
\hline Bioplastic 1 & 30 & 400 & Hydrochloric Acid & Analytical Grade Glycerol \\
Bioplastic 2 & 30 & 400 & Hydrochloric Acid & Locally Purified Glycerol \\
Bioplastic 3 & 30 & 400 & Acetic Acid & Locally Purified Glycerol \\
\hline
\end{tabular}

\section{Results}

Figure 1 shows the physical effect of decomposition on the three bioplastics. The physical appearance over the degradation period started with an increase in thickness due absorption of water followed by darkening due to mixture with soil particles. This was followed by disintegration of the bioplastics into smaller pieces until they were completely broken down. The disintegration of the bioplastics enabled attachment of soil organisms to digest the starch films. By the third week, there was significant disintegration into smaller pieces. In the fifth week Bioplastic 1 was reduced to very small brittle particles that were completely broken down within that week. Figure 1 displays images to the fifth week because the remaining portions were too small to be photo grappled clearly. The other two bioplastics persisted up-to weeks 10 and 11 respectively at which point they were completed degraded.

\subsection{Change in Bioplastic Weight}

Figure 2 shows the changes in weight of the buried Bioplastics over time. The degradation trend for all the bioplastics starts with an increase in weight, followed by mixed variations and then a general decrease in weight until the whole bioplastic is completely broken down. As the hydrophilic enzymes break down the bioplastic its weight initially increases due to absorption of moisture followed by mixed trend of increasing and decreasing phases set in. The mixed trends are a result of the weather variation especially rainfall and temperature changes. Starch being hydrophilic its weight varied with soil moisture levels as the weather parameters that directly influence the moisture levels changed. After moisture has disintegrated the bioplastics, soil organisms digest the bioplastics until they are completely decomposed. Starch being hydrophilic, moisture played a significant role in the whole degradation process and aided the activity of soil microbes. The drastic reduction in weight of the bioplastics after the 3rd week was due to invasion of soil organisms. Worms ingested bioplastic 1, termites ingested bioplastic 2 and bioplastic 3 was decomposed by fungus in the 4th week these aided the complete breakdown of these starch films throughout the 10 weeks. The rate of degradation was slower in the first 3 weeks because there were no visible microorganisms but the presence of water enhanced the disintegration of the bioplastics into the soil and facilitated hydrophilic enzymatic function to breakdown the polymer. The bioplastic made from locally purified glycerol and hydrolyzed with acetic acid had a minor weight variance throughout the ten weeks unlike those hydrolyzed with $\mathrm{HCl}$. $\mathrm{HCl}$ being a strong 


\begin{tabular}{|l|l|l|l|l|l|l}
\hline Date & & Week 1 & Week 2 & Week 3 & Week 4 & Week 5 \\
\hline Bioplastic 1 & & & & & & \\
\hline $\begin{array}{l}\text { Change in } \\
\text { Weight (1) }\end{array}$ & $8.03 \pm 4.75 \mathrm{~g}$ & $11.57 \pm 4.75 \mathrm{~g}$ & $12.19 \pm 4.75 \mathrm{~g}$ & $12.5 \pm 4.75 \mathrm{~g}$ & $7.06 \pm 4.75 \mathrm{~g}$ & $0.058 \pm 4.75 \mathrm{~g}$ \\
\hline Bioplastic 2 & & & & & & \\
\hline
\end{tabular}

Figure 1. Pictorial showing weekly physical changes of the bioplastics in natural environment for the first 5 weeks.

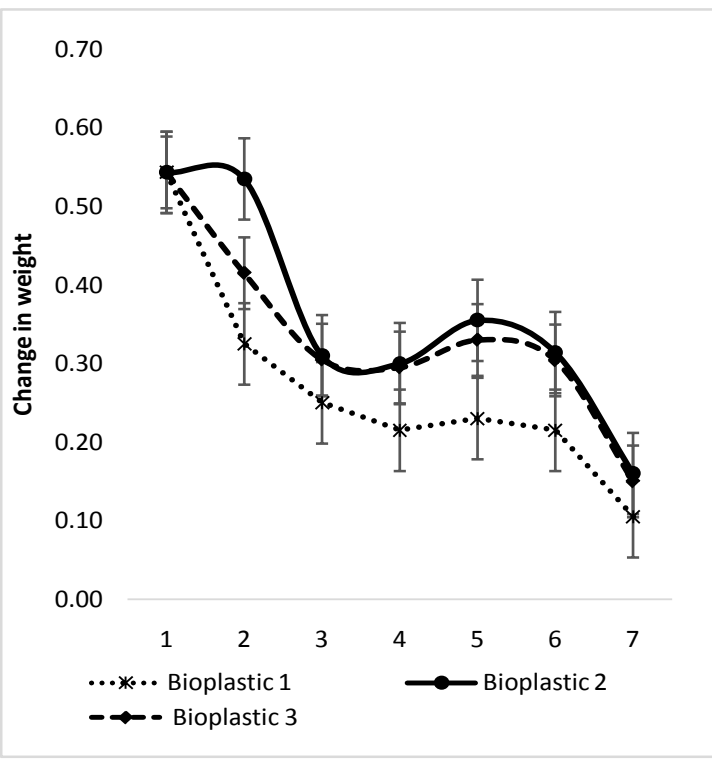

(a)

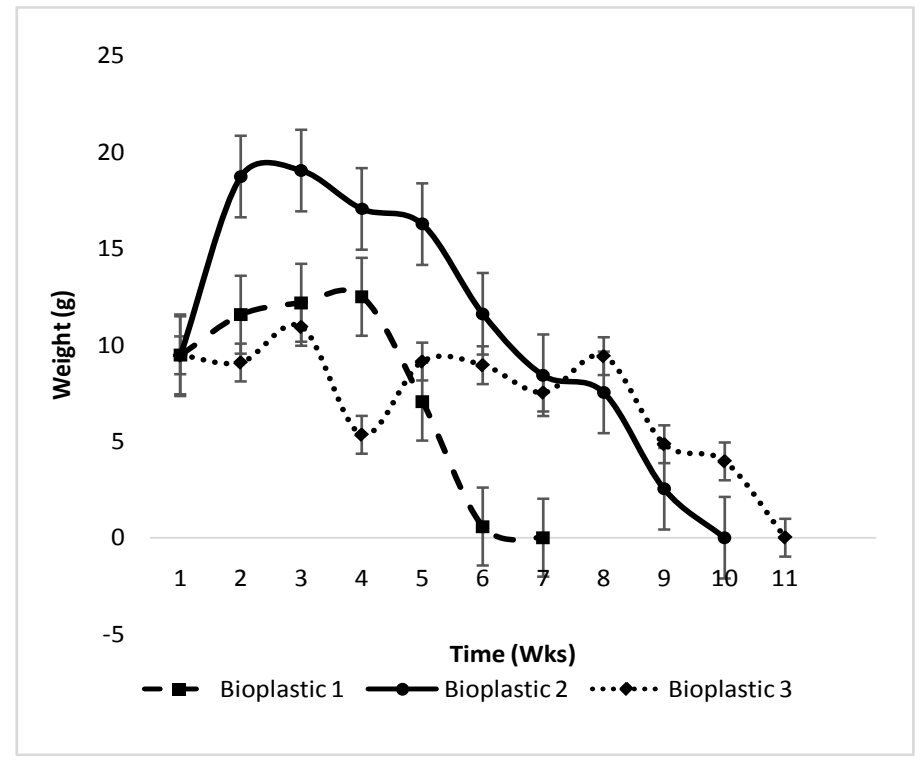

(b)

Figure 2. Change in Bioplastic weight over the period of degradation. (a): bioplastics in laboratory soil and (b): bioplastics in natural environment.

acid absorbs more water over time for all its molecules to dissociate in water and form ions which is the probable reason for the significant variation.

For the laboratory set up, the bioplastics followed a different degradation trend from the natural environment (Figure 2). The bioplastic weight decreased consistently and continuously until all the three types of bioplastics were broken down. The weight of the Bioplastic $1 \& 3$ for the first three weeks declined sharply 
yet Bioplastic 2 had a mixed trend of increasing and decreasing weights. All the three bioplastic then slightly increased in weight in weeks $4 \& 5$ after which their weight declined until all of them were completely broken down.

\subsection{Effect of Weather on Bioplastic Degradation}

The weather parameters varied as follows during the ten week degradation period; rainfall $(0.0-43 \mathrm{~mm})$, daily average temperature $\left(15^{\circ} \mathrm{C}-33.5^{\circ} \mathrm{C}\right)$, relative humidity $(61.5 \%-84.5 \%)$, and sunshine hours $(0.0-8.8 \mathrm{hrs})$. A strong positive correlation was observed for rainfall and change in weight for bioplastic 2 ( $r=$ $0.857)$ and bioplastic $1(r=0.364)$ whereas for bioplastic 3 had a weak correlation $(r=0.018)$. This suggests that rainfall facilitates the degradation of the bioplastics by adding moisture to dissociate the hydrophilic starch films. Temperature also had a strong positive correlation with change in weight for bioplastic 1 $(r=0.677)$ and bioplastic $2(r=0.373)$; however bioplastic 3 was negative $(r=$ -0.158 ). Relative humidity was negatively correlated with change in weight for all the three bioplastics which was the similar case for sunshine hours with bioplastic 1 and 2 but significantly positive for bioplastic $3(r=0.515)$ as shown in Table 2.

\subsection{Relative Humidity \& Temperature Contribution to Degradation}

The bioplastic weight decreased as the relative humidity increased in the first three weeks for all the bioplastics. From the 4th week to 7 th, the weight started to increase with an increase in relative humidity with minimal variations until the 8th week where both $\mathrm{RH}$ and bioplastic weight decreased until the bioplastics were completely broken down (Figure 3 ). Analysis indicates that this is most likely due to increase in soil moisture allowing for more water uptake by the bioplastics. In regard to biodegradability, the moisture absorbed creates optimal conditions for enzyme activity, thereby speeding up the degradation process.

The bioplastic weight, on the other hand, didn't vary significantly with temperature throughout the degradation period. For the first three weeks, the temperature increased and decreased as the bioplastic weight was only increasing until the 4th week, when bioplastic weight started to decrease with temperatures up-to the 6th week and the rate of weight reduction stabilized in the 9th week. The fastest rate of degradation was observed between the 3rd to 8th week and the temperatures ranged between $\left(21.5^{\circ} \mathrm{C}-23.5^{\circ} \mathrm{C}\right)$. The increase in temperature, therefore, enhances the rate of bioplastic weight loss but very high temperatures $\left(50^{\circ} \mathrm{C} \&\right.$ above) slow down the process due reduced soil moisture levels, which inhibits the function of hydrophilic enzymes. However, other moisture independent soil organisms like termites were observed which consumed and broke down the bioplastics. Atmospheric temperatures indirectly affect the degradation in the soil because it directly influences soil moisture. The lower the temperature, the faster the rate of bioplastic degradation until a point beyond which the microbes can't function optimally. 
Table 2. Correlation of Weather parameters with Weight over the degradation period.

\begin{tabular}{ccc}
\hline Bioplastic & Weather Parameter & Correlation (r) \\
\hline & Relative Humidity & -0.301 \\
& Temperature & 0.677 \\
& S SHR & -0.249 \\
Bioplastic 1 & Rainfall & 0.364 \\
\hline & Relative Humidity & -0.441 \\
& Temperature & 0.373 \\
Bioplastic 2 & S SHR & -0.196 \\
& Rainfall & 0.857 \\
\hline & Relative Humidity & -0.040 \\
& Temperature & -0.158 \\
Bioplastic 3 & S SHR & 0.515 \\
\hline
\end{tabular}

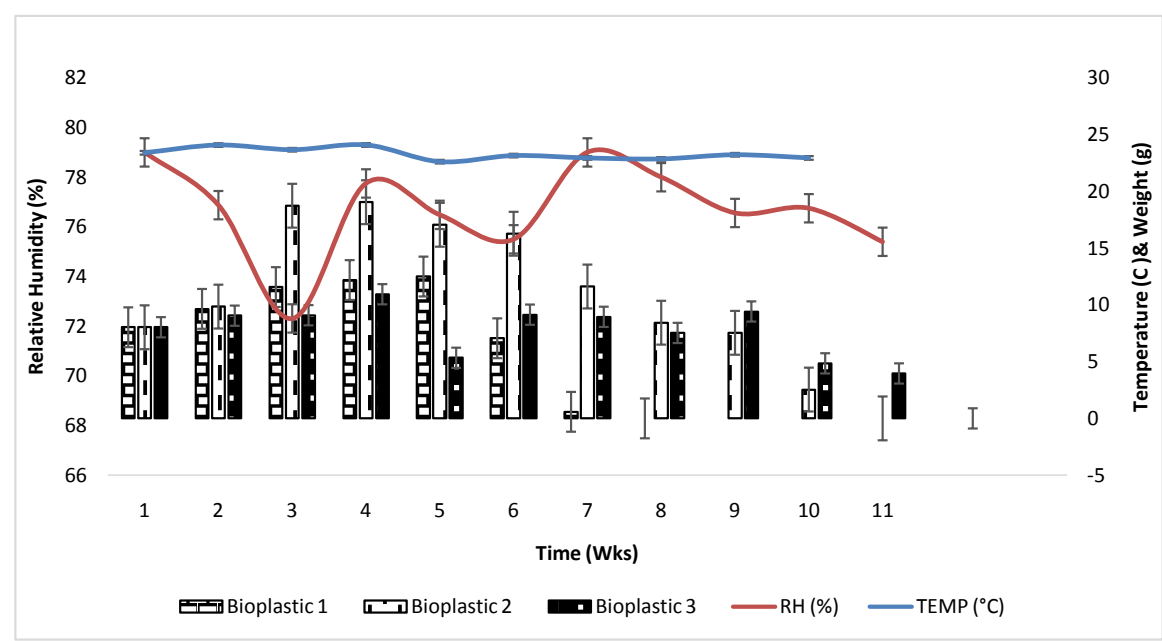

Figure 3. Influence of relative humidity $(\mathrm{RH})$ and temperature on the rate of degradation of the bioplastics.

\subsection{Rainfall \& Sunshine Hours Contribution to Degradation}

The degradation period started with low volumes of rainfall $(2.3 \mathrm{~mm})$. The bioplastic weight was increasing with a decreasing volume of rainfall for the first two weeks. The trend changed after the 2 nd week where bioplastic weight significantly increased with rainfall $(6.05 \mathrm{~mm})$ up-to the 4 th week. From the 4 th to 9th week the bioplastic weight started to decrease with reducing volumes of precipitation and the volumes of rainfall remained low until the bioplastics were completely broken down (Figure 4). The presence of moisture facilitates bioplastic degradation. At first, the weight of a larger bioplastic increased because of absorbing moisture from the soil that was added by rainfall. This created optimal conditions for hydrophilic enzymes to breakdown starch bioplastics. The slowest 


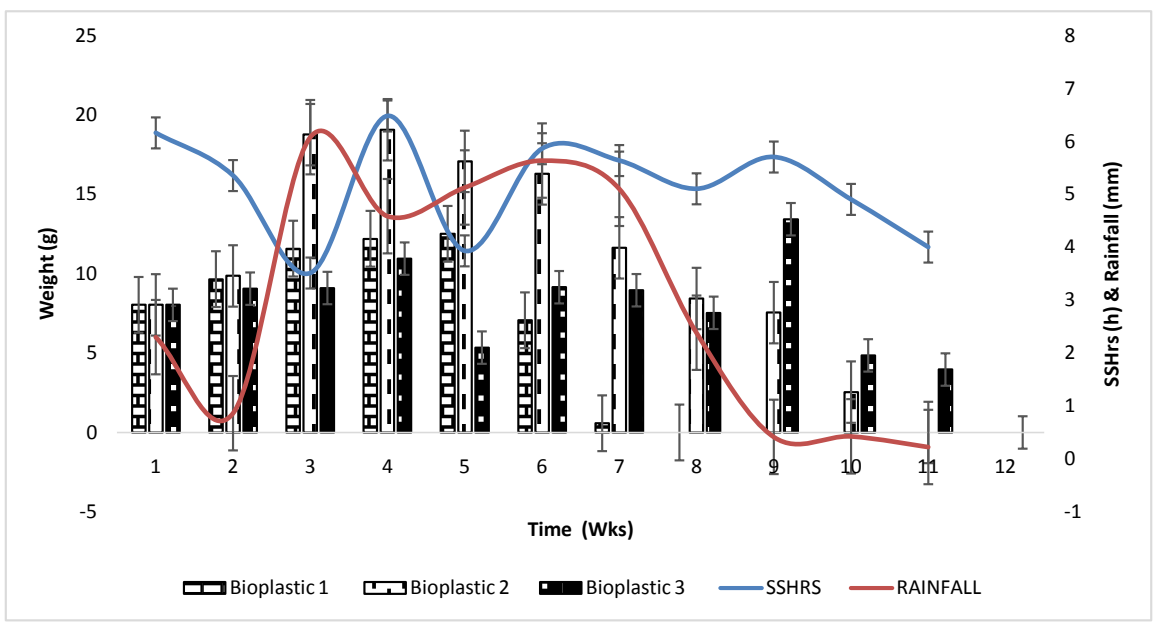

Figure 4. Influence of rainfall and sunshine Hourson the rate of degradation of the bioplastics.

rate of weight reduction was registered when the rains reduced significantly (4th to 7th week). As the bigger percentage of the bioplastic is degraded, the smaller disintegrated pieces created a larger volume to surface ratio for absorption of moisture and digestion by soil organisms.

The bioplastic weight increased with reducing sunshine hours at the start of the degradation (Figure 4). A mixed trend of increasing and decreasing bioplastic weight set in and continued to the 6th week but a steady decline in bioplastic weight was observed until the bioplastics was completely broken down. Sufficient exposure to soil organisms and sunshine increases biological activity, hence facilitating the breakdown of soil substrates. The bioplastic was quickly broken down with moderate sunshine hours from (4 to 6 hrs.) which allowed sufficient moisture to be retained in the soil to facilitate activity of the hydrophilic enzymes. The organisms in the soil once exposed to enough sunshine they are triggered to optimal operation but with excessive exposure they burrow deeper in the soil yet the bioplastic was buried $15 \mathrm{~cm}$ deep. It was observed that the degradation trend increases as the sunshine hours reduced from 6 to 3 hours. Long sunshine hours increased soil temperature which in turn increases the microbial activity leading to an increase the bioplastic's rate of degradation but beyond 6 hours the rate of degradation was slightly slowed down implying excessive sunlight inhibit soil organism activity.

\subsection{Laboratory Degradation Trend for Bioplastics in Water}

All the bioplastics in distilled and tap water increased in weight from $1^{\text {st }}$ to 3 rd week as shown in Figure 5. This was followed by a constant decline in the bioplastic weight from the 4 th until the 8 th week when the bioplastic in distilled water was completely disintegrated and dissolved. Figure 5 also shows the bioplastics in tap water, on the other hand, increased in weight from the $1^{\text {st }}$ to the 2 nd week and their weight started to decline in the 3rd week until they were completely disintegrated and dissolved in the 5th week. Bioplastics in distilled water 
3

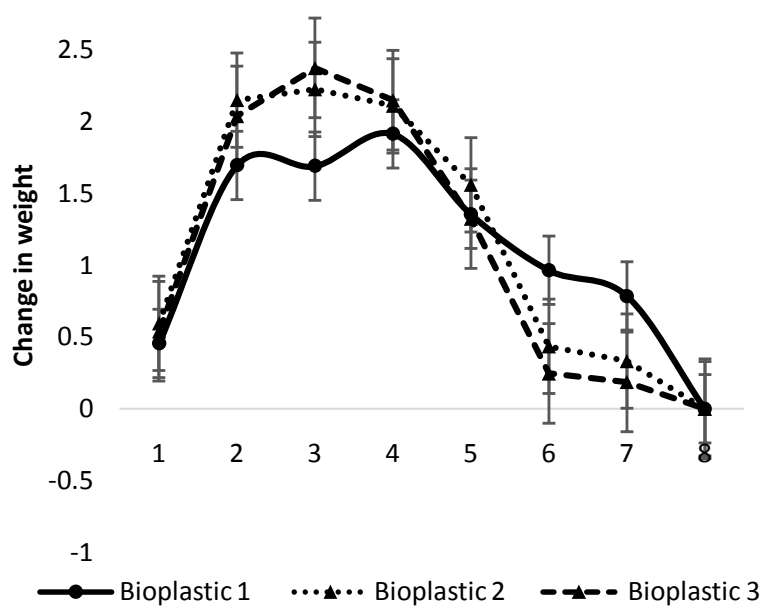

(a)
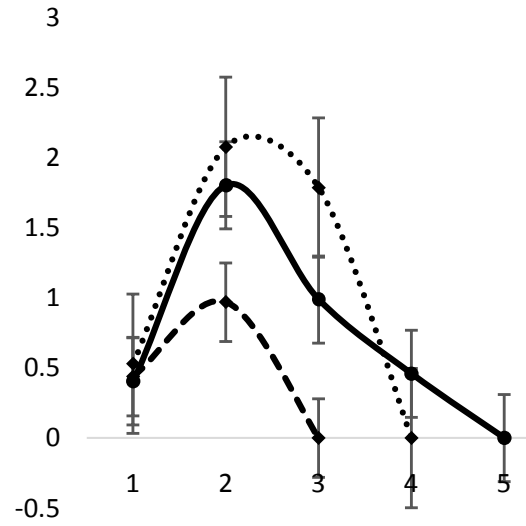

$-1$ Bioplastic 1 $\rightarrow-$ Bioplastic 3

(b)

Figure 5. Laboratory degradation of bioplastics in water, (a): bioplastics in Distilled water and (b): bioplastic in tap water.

and tap water both absorbed high volumes of water for the first two weeks, enough to initiate the enzyme activity. Their weight started to decrease after the third week as the degradation set in. Bioplastic 3 (Figure 5) which was hydrolyzed with acetic acid was dissolved and disintegrated in a shorter time as compared to one and two. In distilled water there was no significant difference among the three plastics, they all followed a similar trend with proportionate increase and decrease in weight until they were completely broken down in the 8th week.

The water-based and soil-based laboratory experiments for bioplastic degradation of made with locally purified glycerol and commercial glycerol varied. It was established that highly pure glycerol takes a shorter period of degradation as seen in the reduced degradation time of the bioplastics made with commercial grade glycerol. This suggests that the purity of glycerol and the hydrolyzing agents directly impact on the rate of degradation of bioplastic.

\section{Discussion}

Plastics of natural origin are referred to as 'Bioplastics'. These are abundant in nature and are either derived directly from biological systems or chemically synthesized from biological building blocks [12]. Starch is one of the major building blocks in bioplastic production. Starch degradation pattern is important to obtain controlled-discharge, help reduce the time required for the plastic to disappear from the environment and give insight on design of starch materials for different purposes with desirable degradation rates [20]. The process of degradation starts with bio-assimilation of the polyesters followed by a biotic hydrolysis where soil organisms transform long polymeric chains into monomeric and oligomeric products that can be easily absorbed by microorganisms [16]. Soil organisms like bacteria, fungi, worms and termites played an active role in the breakdown of the bioplastics at the three sites in Namulonge. The process of 
degradation was highly facilitated by several soil organisms both visible and invisible to the human eye. The organisms begun consuming the bioplastics in the second week leading to a significant drop in the bioplastic weight over time. The degradation started by assimilation in the soil followed by abiotic hydrolysis and the polymer was reduced to digestible forms for microbial uptake [16].

Natural environment degradation procedures are less repeatable but timeefficient as compared with enzymatic degradation [13]. This study with the available resources opted for natural environment degradation in comparison with laboratory degradation set ups. The observed degradation of bioplastics for the entire period took very many twists because it is difficult to control the environmental factors such as temperature, $\mathrm{pH}$, and humidity and microbe populations. Starch being highly hydrophilic, as the hydrophilic enzymes break down the bioplastic, its weight initially increases due to absorption of moisture. The presence of moisture not only disintegrates the bioplastics but also brings about optimal conditions for enzyme activity that further enhances the degradation [13].

Different soil types vary in composition and host diverse microbes which facilitate bioplastic degradation. The porous moist soils which host a large number of soil organisms doubled the rate of degradation of any organic substrate [21]. The multiple microbes around bioplastic 1 increased its rate of degradation shortening its period of assimilation in the soil. As the soils get less aerated and dehydrated, the number of microbes decline and the scarcity of microbes elongate the process of bioplastic breakdown. This was seen when the rains were less which reduced soil moisture and the rate of degradation was slower. Furthermore, bioplastic 2 and 3 which though in the same soil type as 1 were in less moist soils which could have extended their degradation up to ten weeks

Bioplastic strength as informed by the mechanical properties also significantly contributes to the rate of degradation [22]. Bioplastics with increased tensile strength and modulus tend to last longer in any degrading medium. However, water proved to dissolve bioplastics of varying mechanical strength was dissolved within the same period.

Prevailing weather conditions also influence the rate of degradation. Notably, high temperature and relative humidity facilitate hydrolytic degradation. This is because humid conditions encourage soil organism activity; however, severe heat can cause them to burrow deeper in the soil [22]. At high levels of relative humidity, the bioplastic weight increased implying that more humid conditions enhance the water uptake by the bioplastic speeding its disintegration. The bioplastic degradation was influenced by an increase in precipitation since rainfall adds moisture to the soil and the bioplastic is broken down by hydrophilic enzymes [2]. Soil and atmosphere temperature directly influences soil organism activity. Moderate temperatures are conducive for optimal functioning of most soil organisms which enhances the degradation process of a bioplastic but very high temperatures slow it down. This because they reduce moisture levels in the soil inhibiting the hydrophilic enzymes function but other moisture independent 
soil organisms like termites take occasion and breakdown the bioplastics. This suggests that different soil microbes, favored by varying weather condition, all contribute to the general breakdown of the bioplastic over time. The bacteria in the soil, once exposed to enough sunshine, may be triggered to optimal operation but with excessive exposure to the sunshine, they burrow deeper in the soil. Optimal operation of these microbes implies maximum degradation of the bioplastic but this is achieved in the presence of favorable weather and ambient conditions. Meteorological factors like atmospheric temperature, relative humidity and wind speed may account for approximately $35.7 \%$ of the variation of the soil organism activity [21]. This implies that the observed degradation of the bioplastics was greatly facilitated by the meteorological factors followed by soil conditions and the nature of the bioplastics.

\section{Conclusion}

Efforts to battle plastic pollution need be fully accepted and acted upon by an in increase production of suitable substitutes. Fast degrading materials like starch should be given priority as raw materials for production of alternative plastic. Soil and water offer unique degradation profiles for bioplastics but water is a better medium for bioplastic degradation because starch is hydrophilic and can be completely dissolved within four to eight weeks. Healthy well moist soil with multiple organisms, on the other hand, can also breakdown the bioplastics within five to ten weeks All the three bioplastics were completely broken down in natural conditions but bioplastic 2 took longer to degrade in the same conditions implying it is stronger and therefore ideal for tougher applications. The degradation findings are novel in that they reveal that it takes five to ten weeks to fully degrade a starch bioplastic produced from cassava starch and plasticized with locally purified glycerol. This degradation occurred under varying temperature, rainfall, sunlight and relative humidity. Disintegration of the plastic in the soil started at on the in the 2 nd week but when in water it was completely dissolved in five weeks. Water absorbance is strongly dependent on the relative humidity and plasticizer content. In the case of thermal starch being highly hydrophilic it was revealed that disintegration occurs faster with an increase in moisture. Starches based bioplastics with or without additives are highly portentous plastics and continuous improvement will avail the world with sustainable products to check the gross plastic dilemma.

\section{Recommendations}

Studies to understand any possible reactions of these bioplastics with food, water or any substance they may be used to package need to be undertaken to elucidate their behavior under different storage conditions like refrigeration, direct sunlight and heat.

Different ecological zones present varying environmental conditions for degradation of biomass. Therefore, there is a need to study the degradation behavior of these bioplastics under different climatic and environmental zones. Addi- 
tionally, further studies on degradation should be undertaken to determine structural changes in the starch as it breaks down.

\section{Acknowledgments}

The authors wish to acknowledge DAAD for the research funds and the master's scholarship and the National Crops Resources Research Institute for hosting the research experiments. The authors also wish to acknowledge the team in the Nutritional and Bioanalytical Laboratory at NaCRRI and the team at the Materials Engineering Laboratory at the University of Kentucky for the support during the experiments. The contributions of Mr. Isaac Newton Mwebaze, Mr, Wembabazi Enock, Mr. Yusuf Mukasa, Ms. Rose Amwano, Ms. Justine Namayanja Ms. Betty Nalukwago and Ms. Jane Aol during experimentation and data collection are gratefully acknowledged.

\section{Conflicts of Interest}

The authors declare no conflicts of interest regarding the publication of this paper.

\section{References}

[1] Crawford, C.B. and Quinn, B. (2017) Plastic Production, Waste and Legislation. In: Crawford, C.B. and Quinn, B., Eds., Microplastic Pollutants, Elsevier Science, Amsterdam, 39-56. https://doi.org/10.1016/B978-0-12-809406-8.00003-7

[2] Mark, H.F. and Bikales, N.M. (2005) Degradation. In: Encyclopedia of Polymer Science and Technology, John Wiley \& Sons, Inc., Hoboken, 1-44. https://doi.org/10.1002/0471440264.pst093

[3] Gross, M. (2013) Plastic Waste Is All at Sea. Current Biology, 23, R135-R137. https://doi.org/10.1016/j.cub.2013.01.070

[4] Jambeck, J.R., Geyer, R., Wilcox, C., et al. (2015) The Ocean. Science, 347, 768-771. https://doi.org/10.1126/science.1260352

[5] Derraik, J.G.B. (2002) The Pollution of the Marine Environment by Plastic Debris: A Review. Marine Pollution Bulletin, 44, 842-852. https://doi.org/10.1016/S0025-326X(02)00220-5

[6] Webb, H.K., Arnott, J., Crawford, R.J. and Ivanova, E.P. (2013) Plastic Degradation and Its Environmental Implications with Special Reference to Poly(ethylene terephthalate). Polymers (Basel), 5, 1-18. https://doi.org/10.3390/polym5010001

[7] Demirbas, A. (2007) Biodegradable Plastics from Renewable Resources. Energy Sources, Part A: Recovery, Utilization, and Environmental Effects, 29, 419-424. https://doi.org/10.1080/009083190965820

[8] Lörcks, J. (2002) Properties and Applications of Compostable Starch-Based Plastic Material. Polymer Degradation and Stability, 59, 245-249. https://doi.org/10.1016/S0141-3910(97)00168-7

[9] Sagnelli, D., Hebelstrup, K.H., Leroy, E., et al. (2016) Plant-Crafted Starches for Bioplastics Production. Carbohydrate Polymers, 152, 398-408. https://doi.org/10.1016/j.carbpol.2016.07.039

[10] Ashter, S.A. (2016) Types of Biodegradable Polymers. In: Ashter, S.A., Ed., Introduction to Bioplastics Engineering, William Andrew, Amsterdam, 81-151. 
https://doi.org/10.1016/B978-0-323-39396-6.00005-1

[11] Zhou, X., Yang, R., Wang, B. and Chen, K. (2019) Development and Characterization of Bilayer Films Based on Pea Starch/Polylactic Acid and Use in the Cherry Tomatoes Packaging. Carbohydrate Polymers, 222, Article ID: 114912. https://doi.org/10.1016/j.carbpol.2019.05.042

[12] Harma, A.K. (2017) Biopolymers in Drug Delivery. Biopolymers Research, 1, 1-2. https://doi.org/10.4172/2155-9864.1000101

[13] Shah, A.A., Hasan, F., Hameed, A. and Ahmed, S. (2008) Biological Degradation of Plastics: A Comprehensive Review. Biotechnology Advances, 26, 246-265. https://doi.org/10.1016/j.biotechadv.2007.12.005

[14] Müller, C.M.O., Laurindo, J.B. and Yamashita, F. (2012) Composites of Thermoplastic Starch and Nanoclays Produced by Extrusion and Thermopressing. Carbohydrate Polymers, 89, 504-510. https://doi.org/10.1016/j.carbpol.2012.03.035

[15] Singh, J., Dartois, A. and Kaur, L. (2010) Starch Digestibility in Food Matrix: A Review. Trends in Food Science \& Technology, 21, 168-180.

https://doi.org/10.1016/j.tifs.2009.12.001

[16] Emadian, S.M., Onay, T.T. and Demirel, B. (2017) Biodegradation of Bioplastics in Natural Environments. Waste Management, 59, 526-536. https://doi.org/10.1016/j.wasman.2016.10.006

[17] Nuwamanya, E., Baguma, Y., Wembabazi, E. and Rubaihayo, P. (2011) Comparative Study of the Physicochemical Properties of Starches from Root, Tuber and Cereal Crops. African Journal of Biotechnology, 10, 12018-12030.

[18] Nanda, M., Yuan, Z., Qin, W., Poirier, M.A. and Xu, C. (2015) Purification of Crude Glycerol Using Acidification: Effects of Acid Types and Product Characterization. Austin Journal of Chemical Engineering, 1, 1004.

[19] Abolibda, T.Z. (2015) Physical and Chemical Investigations of Starch Based BioPlastics. Thesis, University of Leicester, Leicester, 2-29.

[20] Smirnova, J., Fernie, A.R. and Steup, M. (2015) Starch Degradation. In: Nakamura, Y., Ed., Starch: Metabolism and Structure, Springer, Berlin, 239-290. https://doi.org/10.1007/978-4-431-55495-0_7

[21] Rudnik, E. and Briassoulis, D. (2011) Degradation Behaviour of Poly(lactic acid) Films and Fibres in Soil under Mediterranean Field Conditions and Laboratory Simulations Testing. Industrial Crops and Products, 33, 648-658. https://doi.org/10.1016/j.indcrop.2010.12.031

[22] Fettke, J., Hejazi, M., Smirnova, J., Höchel, E., Stage, M. and Steup, M. (2009) Eukaryotic Starch Degradation: Integration of Plastidial and Cytosolic Pathways. Journal of Experimental Botany, 60, 2907-2922. https://doi.org/10.1093/jxb/erp054

[23] Hoshino, A., Sawada, H., Yokota, M., Tsuji, M., Fukuda, K. and Kimura, M. (2001) Influence of Weather Conditions and Soil Properties on Degradation of Biodegradable Plastics in Soil. Soil Science and Plant Nutrition, 47, 35-43. https://doi.org/10.1080/00380768.2001.10408366 